\title{
A REFLEXÃO DIALÉTICA E A FÉ PERCEPTIVA EM MERLEAU-PONTY
}

Jayme Paviani

SÍNTESE - Exame introdutónio das condições de possibilidade de recuperação da racionalidade da experiência sensível posta de lado, desde o início da filosofia, por Platão e Aristóteles, e do papel da reflexão dialética na investigação da fé perceptiva, conforme M. Merleau-Ponty em Le visible e l'invisible.

PALAVRAS-CHAVE - Ontologia do ser préreflexivo. Reflexão dialética. Fé perceptiva. Racionalidade sensivel.
ABSTRACT - Introductory examination of the possibility conditions for both the rescue of the rationality of sensory experience, which was brushed aside, at the dawn of philosophy, by Plato and Aristotle, and for the role of dialectical reflection in the inquiry on perceptual faith according to $\mathrm{M}$. Merleau-Ponty in Le visible et l'invisible.

KEY WORDS - The ontology of pre-reflective being. Dialectical reflection. Perceptual faith. Sensory rationality.

A formulação do problema pode ser introduzida da seguinte maneira:

1. A filosofia de M. Merleau-Ponty, em sua última fase, transforma a descrição fenomenológica da percepção e do corpo próprio num esboço de projeto ontológico do ser pré-reflexivo, anterior a todos os dualismos metafisicos e fixações (em conceitos e enunciados) do conhecimento filosófico e científico. É necessário examinar as condições de elaboração dessa ontologia do sensivel. Em princípio, sem um recurso à linguagem estética, por exemplo, toda ontologia do sensivel só pode ser uma ontologia de base inteligivel. Nesse sentido, desloca-se a ontologia filosófica e as ontologias (regionais) das ciências para o domínio das expressões estéticas. Talvez se possa aproximar tal movimento à experiência de Wittgenstein que passou do Tractatus para as Investigações Filosóficas.

2. A ontologia do ser indiviso ou critica radical dos conceitos e enunciados metafísicos que sustentam uma determina concepção filosófica e científica (implicita e explícita nos textos pontyanos) busca os "motivos" que estão na gênese dos dualismos metafísicos efetivados pelo realismo e pelo intelectualismo, criticados por Merleau-Ponty na Phénoménologie de la perception, mas ainda subsistentes

Professor do Programa de Pós-Graduação em Filosofia da Faculdade de Filosofia e Ciências Humanas PUCRS. 
nos conceitos mistos como corpo-objeto, corpo-sujeito, corpo-linguagem. A busca dos "motivos", antes mesmo da causas últimas ou dos principios, explorando os limites do corpo através da noção de "carne" e da linguagem encarnada na realidade que se dá num só golpe como visível e invisivel, em termos de visão da ciência e da filosofia "normal" pressupõe um novo paradigma filosófico. Caso contrário, o pensamento de Merleau-Ponty se torna incapaz de propor um estatuto de conhecimento fundamentado e justificado.

3. O impasse epistemológico da reflexão pontyana entre o mundo percebido e o descrito exige uma solução. Parece possível encontrar na sua própria obra uma solução filosófica no exame da noção de reflexão dialética. $\mathrm{O}$ impasse provém da renúncia do organon, instrumento lógico, da linguagem e do conhecimento conceitualmente fixo. A filosofia tradicional, via de regra, não alcança o mundo vivido e ignora a fé perceptiva que fornecem as bases para as interrogações de Le visible et l'invisible.

4. Ao recuperar a experiência do "mundo da vida" (Husserl), "das formas de vida" (Witgenstein), do "saber coletivo" (Durkheim), do "fluxo da consciência" (W. James e Brentanto), do sensus commmunis da tradição, enfim, da fé perceptiva, Merleau-Ponty delimita sua concepção da filosofia como interrogação e reflexão. Ele não abandona totalmente a busca de uma fundamentação, ao contrário, ele a desloca para um lugar mais radical daquele fundado por Platão e Aristóteles. Ao esclarecer os pressupostos explorando a noção de carne e do visível quer romper as separações entre o sensivel e o inteligível alargando a noção de racionalidade, buscando um logos estético.

Entende-se melhor o pensamento de M. Merleau-Ponty quando posto em relação ou mesmo "contra" o de Platão e de Aristóteles. Dito de outro modo, a filosofia pontyana investiga aquilo que Platão, Aristóteles e a tradição ocidental deixaram de lado ou subentenderam na elaboração de suas visões teóricas, as crenças ou as "antinomias insolúveis" do "universo confuso do imediato, do vivido ou do homem vital" considerado pela filosofia e pela ciência desprovido de verdade. "O verdadeiro é o objetivo", não o mundo que se vê. O conhecimento rigoroso é o teórico, aquele que é determinado pelas operações autorizadas pelas variáveis ou entidades definidas "a propósito de uma ordem de fatos" (1971, p. 25). Isso posto, Merleau-Ponty afirma que a fé perceptiva é admitida, mas não esclarecida. Nesse sentido, sua filosofia, sua ontologia, diante do entendimento reinante, parece uma provocação. Entretanto, para ele a solução está na reflexão dialética que assume o irrefletido do ato de reflexão. Com essa contribuição pontyana é possivel redimensionar o conhecimento teórico de um modo mais radical.

Antes da reflexão e mesmo para tornar a reflexão possivel é preciso freqüentar ingenuamente o mundo. Na fé perceptiva a "coisa" é transcendente, fora de toda interioridade. Entretanto, "nous voyons les choses mêmes, le monde est cela que nous voyons" (1964, p. 17. Mas, o filósofo reconhece o impasse, a estranheza da fé perceptiva, pois, diz: "se procuramos articulá-la numa tese ou num enunciado, se perguntarmos o que é este "nós", o que é ește "ver" e que é esta "coisa" ou mun- 
do, penetramos num labirinto de dificuldades e contradições" (1964, p. 17; 1971, p. 15).

Na obra inacabada, Le visible et l'invisible, Merleau-Ponty critica o pensamento sartreano e procura elucidar as relações entre dialética e interrogação. Embora suas reflexões tenham como referência a filosofia sartreana, o texto pode ser lido a partir daquilo que põe e supõe em seus enunciados, sem examinar os elementos externos que surgem como "pretexto". No capítulo Interrogação e Dialética, de imediato, Merlea-Ponty expõe sua desconfiança em relação às possibilidades da filosofia. Diz: "La philosophie a cru dépasser les contradictions de la foi perceptive en la mettant en suspens pour dévoiler les motifs qui la soutiennent" (1964, p. 75). Entre outros aspectos, o enunciado declara, primeiro, que a fé perceptiva implica contradições, segundo, que a filosofia acredita ultrapassar, isto é, resolver as contradições da fé perceptiva e, terceiro, que a filosofia suspende a fé perceptiva para poder desvendar os motivos que a sustentam.

Nessa simples frase, fiel ao fluxo do estilo da escrita pontyana, estão presentes e implicados diversos pressupostos. Pressupõe-se uma idéia de filosofia, de fé perceptiva, de contradição e um sentido do uso dos termos que indicam as operações de suspensão (en suspens) e motivos. A elucidação de pressupostos pode nos conduzir a um retomo infinito. Por isso, quer-se apenas delimitar o discurso filosófico que procura se apoiar em certas bases para poder se autocriticar. A filosofia manifesta-se como uma atividade reflexiva capaz de entrar e de sair de si, como dizia Hegel, citado por Merleau-Ponty. Em outros termos, a filosofia enquanto interrogação reflexiva que procura questionar o domínio lógico, conceitual, inaugurado por Aristóteles, enquanto tenta ir além do organon, instrumento, que limita o pensamento, não pode, por sua vez, ser objetivado e simplesmente subentender a fé perceptiva. Nesse sentido, não se pode reduzir o próprio pensamento pontyano a um conjunto de observações, de teses, de razões sob pena de deixar de interrogar o homem e a vida.

Merleau-Ponty esclarece que a filosofia não é um léxico nem se interessa pelas "significações das palavras", não procura substituto verbal para o "mundo que vemos" nem o transforma em "coisa dita". O filósofo interroga e interrogar é fingir ignorar o mundo e a visão do mundo presentes na operação que consiste em tentar fazê-los falar. O filósofo acredita ir além da "ordem do dito e do escrito". Ele não se instala como um lógico no enunciado ou o poeta na palavra. Acredita conduzir as próprias coisas, do fundo de seu silêncio, à expressão. A interrogação filosófica é uma espécie de mergulho na visão do mundo que nos leva a pensar, e que nos faz pensar a partir "dos paradoxos", "dos enigmas figurados", "dos pormenores incompossiveis" do mundo "que nous voyons et que, pourtant, il nous faut apprendre à le voir” (1964, p. 18).

Essas anotações ainda não nos permitem saber suficientemente a tarefa da filosofia, pois sua concepção surge, igualmente, do que Merleau-Ponty entende por "foi perceptive", qualificada como "obscura". Mas, tudo que é obscuro o é em nome de um certo critério de clareza. Talvez o obscuro, como o mistério, seja 0 
claro demais para o entendimento humano. Em todo caso, para Merleau-Ponty, a filosofia e a ciência supõem a fé perceptiva, e só a supõem, sem a esclarecer. A operação do discurso filosófico, inevitável e legítima, consiste em desvendar as contradições, os motivos que sustentam a fé perceptiva ou que a vida subentende.

Para entender a noção de fé perceptiva é necessário observar que MerleauPonty desloca o ponto de partida da filosofia. Não é mais a análise lógica, a reflexão instituída, mas a fé perceptiva um dos pontos de partida. A interrogação filosófica tem a tarefa de mostrar as insuficiências da análise reflexiva. Reflexão e fé perceptiva constituem-se num único movimento. Por isso, a reflexão dialética, como veremos, alcança o mundo percebido, isto é, o fato de que "vemos as coisas mesmas, o mundo é o que vemos" (1964, p. 17). Essa camada de "opiniões" mudas (a doxa platônica) tecem a vida cotidiana, familiar, pressupõem da filosofia "o aprender a vê-la". A reflexão que sustenta a interrogação filosófica não pode substituir a fé perceptiva, mas recorrer constantemente a ela como uma primeira instância, uma fonte do entendimento humano.

A filosofia torna-se falaciosa ao transformar a fé perceptiva numa crença entre outras, "fondée comme une autre sur des raisons, - les raisons que nous avons de penser qu "il y a un monde" (1964, p. 75). A conclusão da percepção vem antes das razões. Essas, as razões, têm a função de manter o lugar do visto pela percepção e socorrê-la quando abalada. Para Merleau-Ponty, "se procuramos as razões é porque "nous n'arrivons plus a voir" (já não conseguimos ver) ou porque fatos como a ilusão nos incitam a recusar a própria evidência perceptiva. Ele diz: "c'est parce que je crois au monde et aux choses d'abord, que je crois à l'ordre et à la conexion de mes pensées" (é porque crio no mundo e nas coisas que acredito na ordẹm e na conexão de meus pensamentos) (1964, p. 76). Mas, uma vez que a fé perceptiva nos dá "o teor e a medida", à reflexão filosófica é levada a procurar, sob a própria reflexão, as razões para acreditar que o filósofo busca em seus pensamentos, isto é, aquém do mundo.

Merleau-Ponty critica esse tipo de reflexão, desde a reflexão psicológica que se afasta das coisas para redescobri-las nos estados de consciência em que elas são dadas até a reflexão consciente de si própria que pretende alcançar pensamentos puros de uma realidade dita objetiva. Tais modos de reflexão são "uma mentira de onde não há regresso". É necessário, com a reflexão, conceber de novo "l'Être-sujet et L'Être même" (1964, p. 76). Dito de outro modo, conceber o Sersujeito e o próprio Ser exige reconstituir "a verdade dos processos reflexionantes". Pois, acredita-se que antes da reflexão, e é isso que a torna possível, há "uma freqüentação ingênua do mundo", o Si para o qual se chega é precedido por um Si alienado. O mundo, as coisas, o que existe, tudo repousa sobre si mesmo, "é exatamente o que é, inteiramente em ato, sem qualquer virtualidade nem potência", isto é, "transcendente", fora de toda interioridade. O existir repousa na indiferença, "na noite da identidade, como em-si puro" (1964, p. 77). Diante disso, a única maneira de assegurar o acesso às coisas, ao mundo é a "purificação total da noção de subjetividade. Mas, como alcançar tal meta? 
Essa maneira de pensar de Sartre que parte da "intuição do Ser como plenitude absoluta" e que concebe o sujeito, a consciência como negatividade e o mundo como positividade, onde um é o Ser e outro é o nada, sendo um e o outro o direito e o avesso do mesmo pensamento, não considera que a reflexão é movimento de passagem entre unidade e diferença, é não-coincidência ou, em outros termos, presença sobre ausência. O próprio sujeito só é na medida em que está entre as coisas e com os outros. Reflexão não é coincidir ccm o pensamento do outro nem anular as distâncias entre exterioridade e interioridade. Definitivamente pensar não é possuir idéias, dispor de idealidades ou conceitos a serviço da identidade do pensamento, mas circunscrever "campos de pensamentos".

Merleau-Ponty, em sua obra inacabada, Le visible et l'invisible, não apresenta uma resposta à experiência do pensar, do refletir que sustenta a passagem entre a fé perceptiva e as razões, entre o sensivel e o inteligivel. O mistério ou enigma da fé perceptiva não pode ser simplesmente pressuposto ou suprimido, é necessánio esclarecê-lo. Pois, a fé perceptiva que envolve o homem natural, experiência radicalmente realista, é o chão do pensamento, da expressão, da intersubjetividade, do tempo, do imaginário e do nascimento da filosofia e da ciência que se propõem a explicar a própria fé perceptiva. Não sendo a fé perceptiva um saber, mas uma crença, toda dúvida metódica, desde Descartes até Husserl, mas também de Platão até Wittgenstein, tende a tomar-se "incredulidade" (1964, p. 209). Na fé perceptiva, o mundo e as coisas são o que vemos. Com a filosofia e a ciência o mundo torna-se objeto de conhecimento e realidade representada e determinada conceitualmente. A teoria converte o "começo" reflexivo em axioma, funda-se a coincidência problemática dos enunciados e do real. Todavia, a filosofia e ciência, a linguagem e o conhecimento teóricos não conseguem jamais a explicação satisfatória. Por serem "incrédulos" com a fé perceptiva, tomam-se infiéis à verdade.

A reflexão filosófica que não leva em conta a percepção perde o que pretende explicar. Torna-se arbitrária ao distinguir graus e ao discriminar o confuso a partir de idéias claras e distintas. Ao diferenciar percepção, pensamento, linguagem, realidade, conhecimento "la philosophie réflexive remplace [substitui] le 'monde' par 'l'être pensé"' (1964, p. 67). A reflexão não pode colocar-se como princípio de toda explicação, ignorando a fé perceptiva que lhe é ponto de apoio, trampolim para o salto da compreensão. Ela deixa de lado a percepção para tornar-se pensamento do perceber e, assim, o mundo permanece exterior ao corpo próprio substituído pela pretensão de que a realidade é interior ao pensamento. A filosofia e a ciência pretendem acabar com o mistério do mundo e converter todo pensamento em conhecimento objetivo. $\mathrm{Na}$ realidade, para Merleau-Ponty, o mundo percebido está aquém e além dos dualismos do realismo e do intelectualismo, do ser-objeto e do ser-sujeito.

A fé perceptiva pressupõe uma crítica permanente a noções de conceito, idéia, representação, sujeito, consciência, consciência de si, e sua substituição por pensamentos não institucionalizados, por pensamentos que não são enunciados ou juizos, mas dimensões, articulações, configurações do Ser (1964, p. 28 a 30). A filosofia pretende resolver as contradições da fé perceptiva desvendando os "moti- 
vos". que a sustentam. No entanto, para Merleau-Ponty, toda filosofia gira em torno de um "motivo central" e não conceito central. O motivo aparece como "origem" e não causa, como orientação de sentido, como inquietação diante da indeterminação da experiência, do vivido. Para captar o motivo é necessário romper os conceitos, recriá-los, examiná-los no avesso, na gênese.

A negatividade sartreana da dicotomia Ser e Nada, e da filosofia e da ciência em geral, a reflexão dialética admite "que cada termo só é ele mesmo voltando-se para o termo oposto, torna-se o que é pelo movimento". Cada termo é sua própria mediação. O pensamento dialético, desde Heráclito, é capaz de diferenciar e de integrar "num único universo os duplos e até mesmo múltiplos sentidos". O movimento dialético não é simples soma de movimentos opostos nem um terceiro movimento acrescentado a eles, mas "seu sentido comum, os dois movimentos visíveis como um único, tomados totalidade, isto é, espetáculo: "parce que donc la dialectique est pensée de l'Être-vu [Ser-visto], d'un Être qui n 'est pas positivité simple, En Soi, et pas l'Être-pose [Ser-posto], manifestation de Soi, devoilement, en train de se faire (manifestação de $\mathrm{Si}$, desvelamento fazendo-se) (1964, p. 125).

Apesar de não existir, para Merleau-Ponty, uma dialética pura, é tarefa da reflexão dialética, como pensamento situado, denunciar "as falsas evidências", "as significações cortadas da experiência do ser" e criticar-se a si mesma para não se tornar uma dessas experiências vazias. Todo pensamento reduzido a teses é perigoso. As fómulas falsificam o pensamento. Dialética pressupõe identidade e diferença. Quando não existe essa mediação cessa o movimento, a transformação e, desse modo, instala-se a distância entre a fé perceptiva e a reflexão. Boa dialética, diz Merleau-Ponty, é aquela que se critica a si mesma e que tem consciência de que toda tese é idealização,"que l'Être n'est pas fait d'idéalisations ou de choses dites, comme le croyait da vielle logique", mas de conjuntos ligados onde a significação parece apenas como tendência, onde a inércia do conteúdo nunca permite definir um termo como positivo, outro termo como negativo e ainda menos um terceiro termo como supressão absoluta dele por ele mesmo" (1964, p. 129; 1971, p. 96).

Merlau-Ponty retoma às origens, à pistis sem ignorar a noesis platônica que pretendia solucionar o problema da unidade e da multiplicidade, do ser e do nãoser, tendo como fundo o dualismo entre sensivel e inteligivel, ao tentar elucidar as relações entre fé perceptiva e reflexão dialética na investigação do processo interrogativo. Cabe à interrogação filosófica sustentar de modo dialético as relações entre o claro e o obscuro do visivel e do invisível. O esforço interrogativo pontyano quer superar o intuicionismo e o realismo transcendental de Husserl, o dualismo sartreano entre ser e Nada e, de certo modo, todo objetivismo metafísico. Mas ele também se supera a si mesmo, pois, a ordem do percebido não precede a do pensamento, como na Phénomélogie de la perception. A reflexão filosófica envolve num só tempo a fé perceptiva e as razões. Ele não pode se colocar contra o irrefletido. Reflexão e irrefletido constituem-se na reflexão dialética. A filosofia não se reduz à tentativa de pensar a essência e seus pressupostos ontológicos, antes ela precisa alcançar o imediato na mediação. 
A filosofia pontyana, delimitada em sua tarefa, reconhece que o posto de lado, isto é, o mundo da vida, da experiência, desde Platão, é parte fundamental da reflexão filosófica. A filosofia pontyana põe-se como impossibilidade de fazer filosofia no sentido tradicional, instaura-se radicalmente como interrogação. Porém, essa interrogação só pode alcançar um certo êxito ao renunciar os processos lógicos de análise e adotar a reflexão dialética no processo interrogativo. A dialética é entendida aqui de um modo peculiar.

Enquanto o corpo para Platão é um obstáculo de acesso ao mundo inteligível, para Merleau-Ponty, a "carne" é a mediação radical entre o visivel e o invisível. A matemática é o prelúdio da dialética em Platão. Para Merleau-Ponty a dialética qualifica e sustenta a reflexão interrogante. O grande a priori platônico do Bem como causa e princípio universal é substituído pela investigação das origens da fé perceptiva. Não existe uma linha que divide os objetos de crença e da imaginação em relação ao mundo conceitual. Exatamente o ponto abandonado por Platão na construção de seu projeto filosófico torna-se a questão central de Merleau-Ponty. Por isso, em termos amplos é possivel afirmar que estamos, nesse contexto problemático, alcançando o início e o fim da metafísica.

Caracterizada em seu procedimento, a contribuição da filosofia pontyana alarga o entendimento da ciência, mostrando a complexidade do real e da experiência, e reconhece os limites epistemológicos. Quanto à atividade filosófica essa parece se aproximar mais, em sua linguagem, à expressão literária do que à investigação científica. Tal afirmação funda-se na impossibilidade de sistematizar em conceitos e enunciados objetivos a reflexão dialética que se põe em obra na produção do texto filosófico pontyano.

Toma-se necessário esclarecer o que Merleau-Ponty entende por reflexão, conceito, enunciado e muitos outros termos do universo de seu pensamento. De fato, as opções de leitura dessa filosofia são limitadas, pois, ou se objetiva esse pensamento que se quer vivo, em processo, radical em sua tarefa, ou se mergulha no sentido de sua interrogação. Então, a função de explicitar os termos é, como ele explica, um movimento da reflexão dialética.

\section{Referências bibliográficas}

MERLEAU-PONTY, M. Le visible et l'invisible. Paris: Gallimard, 1964.

O visivel e o invisivel. São Paulo: Perspectiva, 1971. 